\title{
Techno-economic analysis of multipurpose OTEC power plants
}

\author{
Stefano Barberis ${ }^{1, *}$, Andrea Giugno ${ }^{1}$, Giacomo Sorzana ${ }^{1}$, Miguel F.P. Lopes ${ }^{2}$ and Alberto \\ Traverso ${ }^{1}$ \\ ${ }^{1}$ University of Genoa, Department of Mechanical Engineering (DIME), Thermochemical Power \\ Group, Via Montallegro 1, 16145 Genova, Italy. \\ ${ }^{2}$ WavEC - Offshore Renewables, Rua Jerónimo Osório 11, 1400-119 Lisboa, Portugal
}

\begin{abstract}
Ocean Thermal Energy Conversion (OTEC) is a promising technology to provide sustainable and dispatchable energy supply to oceanic coastal areas and islands. It exploits the temperature difference between deep cold ocean water and warm tropical surface water in an Organic Rankine Cycle (ORC), guaranteeing a continuous and dispatchable electric production, overcoming one of the most critical issue of renewable generators such as PV or wind turbines. Despite the technological maturity of ORC application to OTEC systems, it still presents technical and economic barriers mainly related to their economic feasibility, large initial investments as well as heavy and time demanding civil installation works. To overcome such issues, multipurpose OTEC plants are proposed, producing electrical power as well as other products, such as useful thermal power (e.g. ambient cooling) and desalinated water. Since OTEC engineering is still at a low degree of maturity, there are no widespread and established tools to facilitate OTEC feasibility studies and to allow performance and cost optimization. Therefore, in this paper, a new tool for techno-economic analysis and optimization of multipurpose OTEC plants is presented. Starting from a detailed database of local water temperature and depth, the approach allows to provide a quantitative insight on the achievable performance, required investment, and expected economic returns, allowing for a preliminary but robust assessment of site potential as well as plant size. After the description of the techno-economic approach and related performance and cost functions, the tool is applied to an OTEC power plant case study in the range of $1 \mathrm{MW}$ gross electrical power, including a preliminary assessment of scaling-up effects.
\end{abstract}

Keywords: Ocean Thermal Energy Conversion, Sea energy, Polygeneration, Oraganic Rankine Cycle

\section{Introduction}

In recent years, energy independency of islands and archipelago has become an important issue for many researchers, particularly analyzing their renewable potential and the possibility to test innovative concepts such as smart grids, energy storages, new power plants and energy efficiency solutions [1]. Among those, Ocean Thermal Energy Conversion (OTEC) technology boasts competitive advantages over alternative sources of electricity production regarding accessibility, predictability, dispatchability and emission.

\footnotetext{
* Corresponding author: barberis.ste@gmail.com
} 
OTEC consists of a process that can produce electricity by using the temperature difference between deep cold ocean water and warm tropical surface water. OTEC plants pump large quantities of seawater to run a power cycle and produce electricity 24/7. Energy produced by OTEC plants can be considered dispatchable providing a reliable energy sources for not connected to National Grid islands [2].OTEC also offers the possibility of cogenerating other synergistic products, like fresh water, nutrients for enhanced fish farming and seawater cooled greenhouses. Cold water can be used also in building air-conditioning systems. Energy savings of up to $90 \%$ can be realized [3]. Careful site selection is a crucial point to keep the environmental impact of OTEC minimal and ensure economic sustainability. Researchers believe that appropriate spacing of plants throughout tropical oceans can nearly eliminate any potential negative effects on ocean temperatures, local ecosystems and marine life [4]. Another factor hindering the commercialization of OTEC is that there are only a few hundred land-based suitable sites in the tropics, where deep-ocean water is close enough to the shore [5]. Therefore, techno-economic tools for site assessment in view of OTEC installations are strategic to reduce survey time, design costs and to allow identifying the locations where energy source and need are well combined. In this paper, a new tool is presented to analyze the techno-economic feasibility of multipurpose OTEC power plants, starting from real monitored seawater data, in order to evaluate the potential of this technology in a straightforward but complete way. The tool is the result of a fruitful collaboration between WAVEC, with its experience in monitoring seawater and map its energy potential [6,7], and the University of Genova, Thermochemical Power Group (TPG), with its background in thermoeconomics and energy district analysis $[8,9]$.

\section{Techno-economic simulation tool}

Since OTEC technology is still under development, to overcome the lack of field data, some technology providers such as Bluerise [10] and Makai [11] have developed tools for a preliminary assessment for the Ocean Thermal Energy. However, there is not available yet a comprehensive tool, not based on a specific technology, for the preliminary techno-economic assessment of OTEC installations.

The tool, developed in the MATLAB ${ }^{\circledR}$-Simulink ${ }^{\circledR}$ environment, provides steady-state thermo-economic analysis of a land-based Closed-Cycle OTEC plant, working with ammonia, along with optional devices (SeaWater Air Conditioning, desalination plant, etc.). Since these optional products, i.e. air conditioning and fresh water, are considered fundamental for the economic sustainability of OTEC technology in the near future, only land-based plants have been considered, disregarding floating plants, where multi-purpose OTEC systems will be less likely realized.

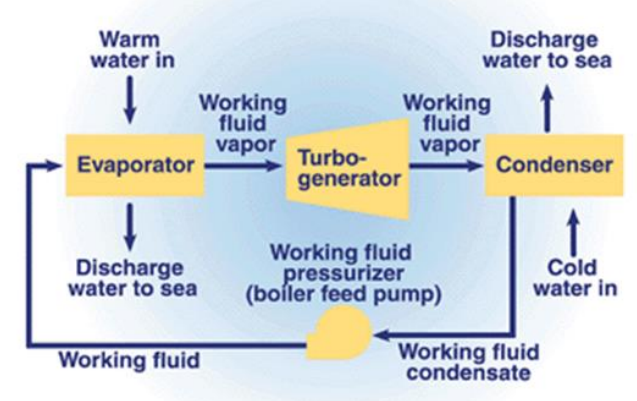

Figure 1: Closed-Cycle OTEC system layout [12] 
Closed-cycle OTEC system [13] can be considered as the "traditional OTEC" plants. This cycle uses a low boiling point fluid, such as ammonia or other organic fluids, to operate a traditional Organic Rankine Cycle (ORC) plant to generate electricity [14]. Warm surface seawater is pumped through a heat exchanger, where the low-boiling-point fluid is vaporized. The expanding vapor turns the turbo-generator. Cold deep seawater, which is pumped through a second heat exchanger, condenses the vapor back into a liquid that is then recycled through the system. The advantages of using a closed-cycle system are compactness and that it can be designed using already existing turbo machinery and heat exchanger designs.

The model incorporates worldwide bathymetry from the NOAA database [15] and seawater temperature monthly maps from the Copernicus database [16], depending on latitude, longitude and depth. This allows to perform techno-economic assessment without any site restriction. The tool receives multiple parameters on the inlet and outlet pipelines, and it carries out a preliminary design of the whole plant, calculating seawater and ammonia mass flows, thermodynamic data of the ORC and its efficiency, etc. Furthermore, it also performs a preliminary plant economic. The simulation process flow diagram of the tool is summarized in Figure 2.

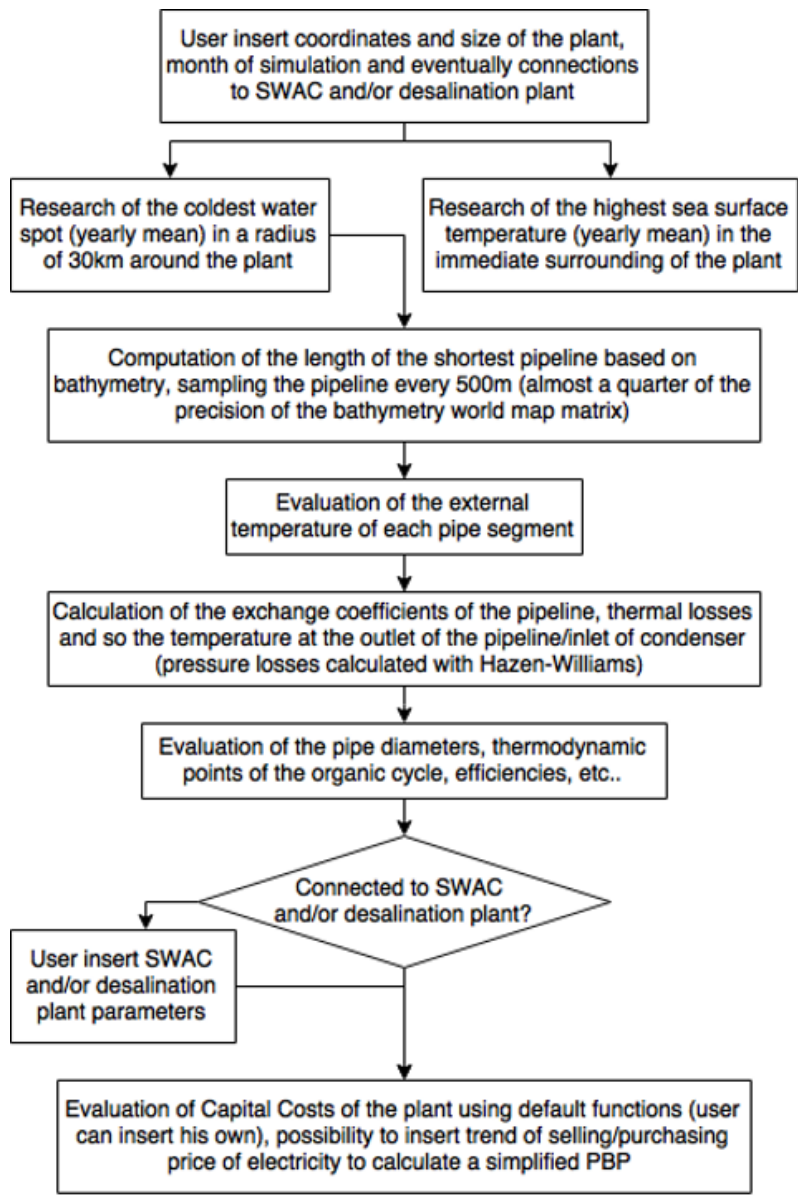

Figure 2: Simulation process flow chart

To capitalize on the discharge cold water of the OTEC plant for other purposes and consider multipurpose OTEC concepts, a SeaWater Air Conditiong (SWAC) system is 
included, which represents a proven technology that uses the cold seawater to cool commercial buildings or residential complexes close to the sea (or lake). The operating variable costs of the plant are nearly independent from future energy price increases, since SWAC requires electrical power that can be directly provided from the OTEC system.

To compute the thermal load required by the SWAC system, three main sources have been considered:

1. Thermal load due to people in the building, lights, electrical devices

2. Specific heat due to the temperature difference between indoor and outdoor air temperature

3. Specific heat through glassy surfaces due to thermal solar irradiation.

To perform then a preliminary economic analysis of the plant, several correlations were developed from industrial reference capital costs [17-22]. The user has the possibility to insert an hourly profile of the electrical power load of the facilities, so that the hourly electrical power that can be sold to the grid can be determined as the difference between the power produced by the ORC and the one consumed by the pumps, considering as well an electrical generator efficiency of $98 \%$.

\section{Case Study}

The techno-economic simulation tool has been used for assessing the energy and economic potential of the following site and multipurpose OTEC plant:

- Location: (longitude: -81.106, latitude: 19.297), close to East End, Cayman Islands

- $\quad$ ORC turbine size: $1 \mathrm{MW}$

Given the worldwide database available in the tool, the plant location can be chosen in any shoreline. For this case study, the plant has been located in order to have good working conditions for OTEC plant (the sea bed around Cayman Islands presents a high slope and so it is possible to have a large difference of temperature between surface and deep water (Figure 3 ) without going too far from the shore) which would highly affect the cost of the pipeline.

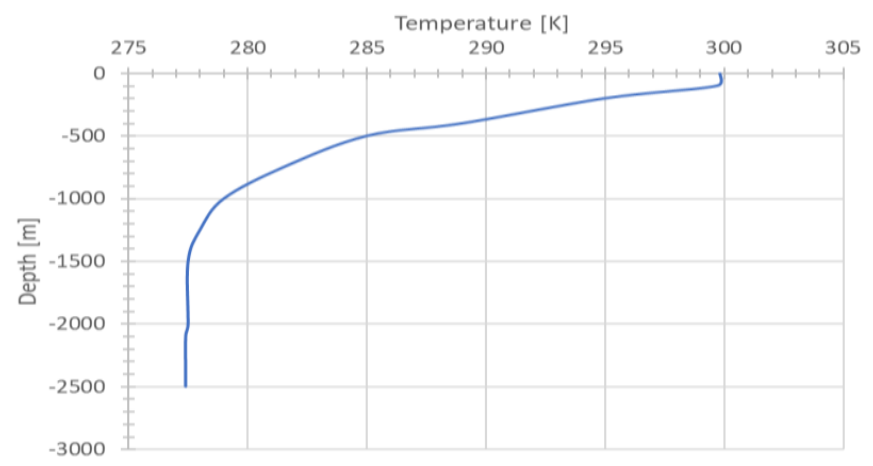

Figure 3: Water temperature trend in the surroundings of the plant

The size of the ORC turbine, $1 \mathrm{MW}$, has been assumed to be in line with the current on-shore working plants and the constraints of the local electrical grid. The approach temperatures at the evaporator and condenser have been fixed in order to obtain the best working solution of the plant: this was verified through iterative simulations, not reported here.

The SWAC system has been coupled to a building with the following characteristics:

- $\quad$ North and south walls: $1000 \mathrm{~m}^{2}$ (half glassy surface)

- $\quad$ East and west walls: $600 \mathrm{~m}^{2}$ (half glassy surface)

- Shading coefficient: 0.77

- $\quad$ Albedo factor: 0.3 
- Set point temperature for cooling: $21^{\circ} \mathrm{C}$

- Occupancy of the building: 1500 people

- Number of installed electrical devices: 200

- $\quad$ Number of high load rooms: 20

- Daily cooling period: 14 hours per day

- Starting time for cooling: 8:00 a.m.

- $\quad$ Surface: $4500 \mathrm{~m}^{2}$

A simplified layout of the case study plant is reported in the following figure:

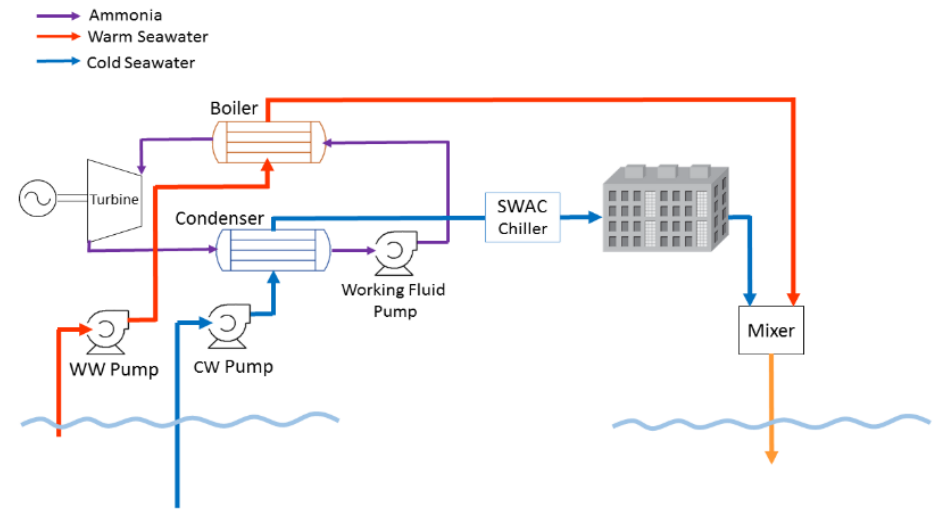

Figure 4: Case study plant layout

A parametric study on the following parameters of the plant was performed in order to look for the lowest total capital cost solution, able to guarantee satisfactory performance:

1. Temperature difference $\Delta \mathrm{T}$ between the cold seawater temperature value at the outlet of the pipeline and the ammonia entering into the condenser: $\Delta$ Tcond $=\{1.5$; $3.0 ; 4.5 ; 6.0\} \mathrm{K}$

2. Flow velocity within cold water pipe: $V c w p=\{1.5 ; 1.6 ; 1.7 ; 1.8 ; 1.9 ; 2.0\} \mathrm{m} / \mathrm{s}$

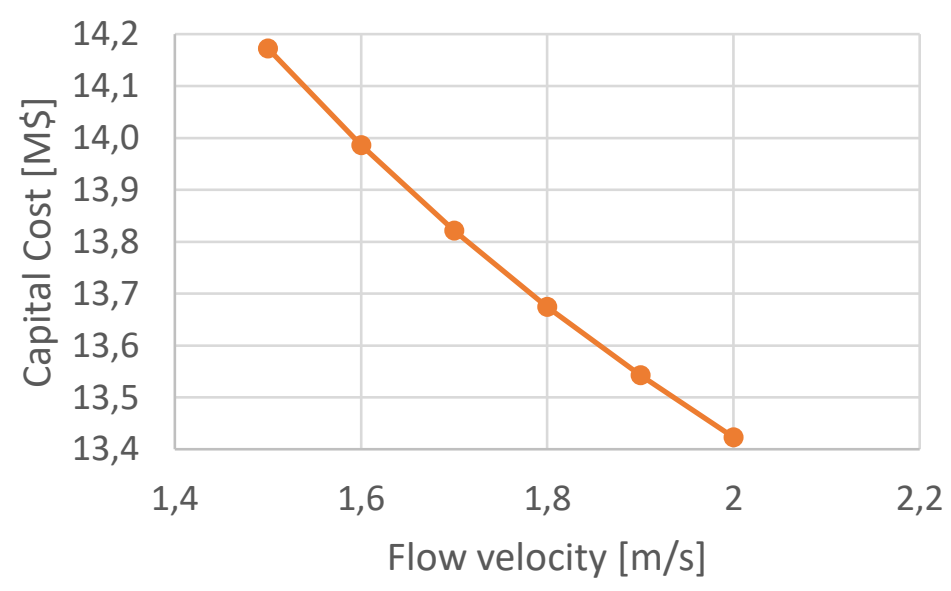

Figure 5: Capital cost of the plant for a $\Delta \mathrm{T}_{\text {cond }}$ of $4.5^{\circ} \mathrm{C}$

From the results, it has been observed that the best case appeared to be for a $\Delta \mathrm{Tcond}$ of $4.5^{\circ} \mathrm{C}$; therefore, this value was fixed for the results presented in the following. It can be observed that for velocities between $1.5 \mathrm{~m} / \mathrm{s}$ and $1.8 \mathrm{~m} / \mathrm{s}$ the slope of the curve is constant, with a variation of about $30 \mathrm{k} \$$ every $0.1 \mathrm{~m} / \mathrm{s}$; after $1.8 \mathrm{~m} / \mathrm{s}$ the variation is lower reaching a minimum 
of $10 \mathrm{k} \$$ between $1.9 \mathrm{~m} / \mathrm{s}$ and $2 \mathrm{~m} / \mathrm{s}$. It is however noticeable how the capital cost of the plant is highly influenced by the design velocity of the water within the pipes, which impacts on their diameters. The plant has been sized on the February conditions, which represent the most demanding period of the OTEC/SWAC plant, both for the lowest temperature difference value between cold and warm seawater and for the cooling system load, considering a $\Delta$ Tcond of $4.5^{\circ} \mathrm{C}$ and a flow velocity of $2 \mathrm{~m} / \mathrm{s}$ The most interesting outputs are listed in the following table.

Table 1: Design conditions of the plant (February reference case)

\begin{tabular}{|c|c|c|c|}
\hline Output parameter & Value & Output parameter & Value \\
\hline$T_{\text {cold,sw,intake }}$ & $279.3 \mathrm{~K}$ & $\begin{array}{l}\text { Warm seawater mass } \\
\text { flow }\end{array}$ & $2477 \mathrm{~kg} / \mathrm{s}$ \\
\hline$T_{\text {warm,sw,intake }}$ & $299.8 \mathrm{~K}$ & Ammonia mass flow & $27.1 \mathrm{~kg} / \mathrm{s}$ \\
\hline Cold pipe length & $1343 \mathrm{~m}$ & $\begin{array}{l}\text { Seawater discharge } \\
\text { depth }\end{array}$ & $271 \mathrm{~m}$ \\
\hline Cold pipe diameter & $1194 \mathrm{~mm}$ & Carnot cycle efficiency & 0.0461 \\
\hline $\begin{array}{l}\text { Cold seawater mass } \\
\text { flow }\end{array}$ & $2307 \mathrm{~kg} / \mathrm{s}$ & OTEC cycle efficiency & 0.0258 \\
\hline $\begin{array}{l}\text { Warm pipe length } \\
\text { Warm pipe diameter }\end{array}$ & $\begin{array}{l}200 \mathrm{~m} \\
1237 \mathrm{~mm}\end{array}$ & Capital cost & $13.42 \mathrm{M} \$$ \\
\hline
\end{tabular}

The overall capital cost (not including discharge pipeline, civil works, installation, land, etc.) can be divided as shown in Figure 6. As expected, pipeline to convey water to the process block is one of the most expensive components of the OTEC plant, even in case of proximity with deep cold water. High costs of seawater pumping systems are related to the extremely high mass flow rates with which the plant operates. On the other hand, SWAC has a limited impact on the overall costs (promising option to increase investment profitability).

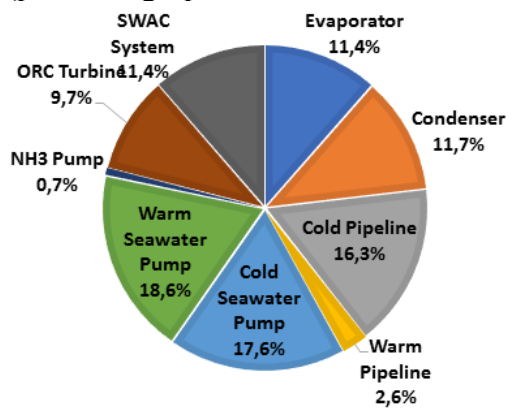

Figure 6: Distribution of capital costs

As it can be seen, even in February the total efficiency of the cycle is good compared to the Carnot one, thanks to the difference of temperature between cold and warm seawater that is higher than 20 degrees, making the selected location a suitable place for the installation of a multi-purpose OTEC system. The plant behaviour is now evaluated during the whole year, in order to evaluate the effects of the variation of the boundary conditions. The most relevant results are reported in the following table: 
Table 2: Annual operating performance

\begin{tabular}{l|lllccccc}
\hline Month & $\begin{array}{c}\text { Cold } \\
\text { pump } \\
\text { power } \\
{[\mathbf{k W}]}\end{array}$ & $\begin{array}{c}\text { Warm } \\
\text { pump } \\
\text { power } \\
{[\mathbf{k W}]}\end{array}$ & $\begin{array}{c}\text { Net } \\
\text { Power } \\
{[\mathbf{k W}]}\end{array}$ & $\begin{array}{c}\text { Cold } \\
\mathbf{T}_{\text {intake }}[\mathbf{K}]\end{array}$ & $\begin{array}{c}\text { Warm } \\
\mathbf{T}_{\text {intake }} \\
{[\mathbf{K}]}\end{array}$ & $\Delta \mathbf{T}$ & $\begin{array}{c}\mathbf{T}_{\text {discharge }} \\
{[\mathbf{K}]}\end{array}$ & $\begin{array}{c}\text { OTEC } \\
\text { efficiency }\end{array}$ \\
\hline January & 106.8 & 18.0 & 867.2 & 279.4 & 300.0 & 20.6 & 290.0 & 0.0263 \\
February & 114.5 & 17.1 & 855.2 & 279.3 & 299.8 & 20.5 & 289.9 & 0.0254 \\
March & 97.3 & 17.7 & 848.4 & 279.4 & 300.0 & 20.6 & 290.0 & 0.0250 \\
April & 67.6 & 7.8 & 865.0 & 279.5 & 300.0 & 20.5 & 290.1 & 0.0259 \\
June & 58.7 & 5.7 & 904.5 & 279.1 & 301.5 & 22.4 & 289.7 & 0.0299 \\
August & 63.3 & 7.5 & 915.6 & 278.9 & 302.1 & 23.2 & 289.6 & 0.0322 \\
October & 85.5 & 12.9 & 909.1 & 279.6 & 302.2 & 22.6 & 290.4 & 0.0312 \\
December & 111.3 & 16.6 & 881.6 & 279.2 & 300.4 & 21.2 & 289.8 & 0.0270 \\
\hline
\end{tabular}

Highlighting the variation of the net power produced by the plant along the months, it can be observed that the highest net power occurs in the months between June and October.

\section{Large size OTEC plants}

In order to evaluate the impact of size on OTEC plant economics, two additional different sizes are considered, for the same installation site: 5 and $10 \mathrm{MW}$ gross power.

The best design values, previously identified, have been considered (i.e. $\Delta$ Tcond $=4.5^{\circ}$, Flow velocity within pipes $=2 \mathrm{~m} / \mathrm{s}$ ).

A comparison between the three plant sizes is summarized in the following table:

Table 3: Large size OTEC plans thermo-economic comparison

\begin{tabular}{lllll}
\hline Variable & SI Unit & $1 \mathrm{MW}$ & $5 \mathrm{MW}$ & $10 \mathrm{MW}$ \\
\hline Cold seawater pipe diameter & $\mathrm{mm}$ & 1195 & 2672 & 3778 \\
Warm seawater pipe diameter & $\mathrm{mm}$ & 1238 & 2766 & 3911 \\
Cold seawater mass flow rate & $\mathrm{kg} / \mathrm{s}$ & 2307 & 11525 & 23046 \\
Warm seawater mass flow rate & $\mathrm{kg} / \mathrm{s}$ & 2477 & 12354 & 24695 \\
Capital cost & $\mathrm{M} \$$ & 13.31 & 49.38 & 90.83 \\
Capital cost per MW (gross power) & $\mathrm{M} \$ \mathrm{MW}$ & 13.31 & 9.88 & 9.08 \\
\hline
\end{tabular}

As expected, increasing the size of the plant is beneficial from the specific capital cost point of view $(\mathrm{M} \$ \mathrm{MW})$. However, the capital costs for large power plants remain high at the current state of the art, and the pipe large diameter may lead to possible issues for near-coast installation.

\section{Conclusions}

In this paper a new simulation tool for the techno-economic analysis of multipurpose OTEC plants has been presented. The main goal is to provide a preliminary evaluation of the thermodynamic and economic performance of the OTEC plant, starting from monitored data of seawater conditions in terms of temperature and depth in a specific installation site.

The tool provides the optimal plant design point as well as the yearly performance, starting from monthly data of seawater. Such an analysis is representative of a higher resolution assessment due to two main facts:

1) The stability of water temperature during a month that guarantees the OTEC plant not to work in strong off-design conditions day-by-day 
2) The almost stable power production of the OTEC plant that can guarantee the baseload as it can work 24/7.

The modeling approach has been introduced, highlighting its capability to evaluate multipurpose OTEC plants: in fact, polygeneration of power, heat/cooling and desalinated water can be considered crucial for the development and spread of OTEC plants, which are still affected by high capital costs, mainly related to the seawater piping and pump system. In particulare, desalination and Sea Water Air Conditioning are two potential by-products that can guarantee additional revenues to OTEC plants

The tool will enable OTEC designers and investors to have a preliminary fast but reliable evaluation of the technical and economic feasibility of an OTEC installation, starting from local marine data.

A case study has been analysed in detail for a $1 \mathrm{MW}$ gross electrical power OTEC, with the following results:

- The efficiency of the cycle along months is around $55-60 \%$ of the Carnot one, achiving the maximum in August at $\eta_{\max }=3.22 \%$

- The Capital Costs of the plant (including SWAC plant) per kW of gross power are affected by a scale factor, in particular:

○ 1 MW plant: $13310 \$ / \mathrm{kW}$

- 5 MW plant: $9880 \$ / \mathrm{kW}$

○ 10 MW plant: $9080 \$ / \mathrm{kW}$

- The plant equivalent operating hours are about 8000 , which make them outstanding in the panorama of other renewable technologies and like the geothermal plants.

The application of the proposed methodology to different sites may help the spread of multipurpose OTEC plants and may optimize the cost effectiveness of each installation, thus contributing to the diffusion of such a technology in the most attractive contexts.

\section{References}

[1] Bénard-Sora, F., and Praene, J. P., 2016, "Territorial Analysis of Energy Consumption of a Small Remote Island: Proposal for Classification and Highlighting Consumption Profiles,” Renew. Sustain. Energy Rev., 59, pp. 636648.

[2] Hossain, M. S., Madlool, N. A., Rahim, N. A., Selvaraj, J., Pandey, A. K., and Khan, A. F., 2016, "Role of Smart Grid in Renewable Energy: An Overview," Renew. Sustain. Energy Rev., 60, pp. 1168-1184.

[3] Osorio, A. F., Arias-Gaviria, J., Devis-Morales, A., Acevedo, D., Velasquez, H. I., and Arango-Aramburo, S., 2016, "Beyond Electricity: The Potential of Ocean Thermal Energy and Ocean Technology Ecoparks in Small Tropical Islands," Energy Policy, 98, pp. 713-724.

[4] Boehlert, G., and Gill, A., 2011, "Environmental and Ecological Effects of Ocean Renewable Energy Development - A Current Synthesis," Oceanography, 23(2), pp. 68-81.

[5] Rajagopalan, K., and Nihous, G. C., 2013, "Estimates of Global Ocean Thermal Energy Conversion (OTEC) Resources Using an Ocean General Circulation Model," Renew. Energy, 50, pp. 532-540.

[6] Nobre, A., Pacheco, M., Jorge, R., Lopes, M. F. P., and Gato, L. M. C., 2009, "Geo-Spatial Multi-Criteria Analysis for Wave Energy Conversion System Deployment," Renew. Energy, 34(1), pp. 97-111.

[7] Simas, T., O’Hagan, A. M., O’Callaghan, J., Hamawi, S., Magagna, D., Bailey, I., Greaves, D., Saulnier, J.-B., Marina, D., Bald, J., Huertas, C., and Sundberg, J., 2015, "Review of Consenting Processes for Ocean Energy in Selected European 
Union Member States,” Int. J. Mar. Energy, 9.

[8] Rivarolo, M., Cuneo, A., Traverso, A., and Massardo, A. F., 2016, "Design Optimisation of Smart Poly-Generation Energy Districts through a Model Based Approach," Appl. Therm. Eng.

[9] Ferrari, M. L., Traverso, A., and Massardo, A. F., 2016, "Smart Polygeneration Grids: Experimental Performance Curves of Different Prime Movers," Appl. Energy.

[10] "Bluerise - Harnessing the Ocean's Power" [Online]. Available: http://www.bluerise.nl/.

[11] "Sea Water Air Conditioning | Makai Ocean Engineering” [Online]. Available: http://www.makai.com/sea-water-air-conditioning/.

[12] Giordani, H. D., Lages, M., Medina, M., and Tan-Holmes, J., 2015, “Affects of the Cold Water Pipe Depth in Ocean Thermal Energy Converter Plants with Respect to Power Generation Efficiency,” PAM Rev. Energy Sci. Technol., 2, p. 50.

[13] Ravindran, M., and Abraham, R., 2016, "Ocean Thermal Energy Conversion," Springer Handbook of Ocean Engineering, pp. 1245-1266.

[14] Tchanche, B. F., Lambrinos, G., Frangoudakis, A., and Papadakis, G., 2011, "LowGrade Heat Conversion into Power Using Organic Rankine Cycles - A Review of Various Applications,” Renew. Sustain. Energy Rev., 15(8), pp. 3963-3979.

[15] "Global Bathymetry Map" [Online]. Available: https://maps.ngdc.noaa.gov/viewers/bathymetry/.

[16] EC-Copernicus, 2016, "Copernicus Marine Environment Monitoring Service," p. 2 [Online]. Available: http://marine.copernicus.eu/.

[17] Jung, J. Y., Lee, H. S., Kim, H. J., Yoo, Y., Choi, W. Y., and Kwak, H. Y., 2016, "Thermoeconomic Analysis of an Ocean Thermal Energy Conversion Plant," Renew. Energy, 86, pp. 1086-1094.

[18] Patterson, L. W., and Banker, R. F., 1971, Estimating Manpower Requirements for Conventional Wastewater Treatment Facilities, Washington, DC.

[19] Loh, H. P., Lyons, J., and Charles W. White, I. I. I., 2002, "Process Equipment Cost Estimation, Final Report,” Other Inf. PBD 1 Jan 2002, (January), p. Medium: ED; Size: 410 Kilobytes pages.

[20] Lemmens, S., 2015, "A Perspective on Costs and Cost Estimation Techniques for Organic Rankine Cycle Systems,” 3rd Int. Semin. ORC Power Syst., (2010), pp. 110.

[21] Elsafty, A., and Saeid, L., 2009, "Sea Water Air Conditioning : A Cost Effective Alternative," Int. J. Eng., 3(3), pp. 346-358.

[22] Reddy, K. V., and Ghaffour, N., 2007, "Overview of the Cost of Desalinated Water and Costing Methodologies," Desalination, 205(1-3), pp. 340-353. 